\title{
DETERMINANTES DA SATISFAÇÃO DO CONSUMIDOR NO PROCESSO DE SELEÇÃO DE ROUPAS INFANTIS. ${ }^{1}$
}

\section{DETERMINATIVE OF THE SATISFACTION OF THE CONSUMER IN THE PROCESS OF ELECTION OF INFANTILE CLOTHES}

\author{
Elias Frederico ${ }^{2}$ \\ Andre Ricardo Robic ${ }^{3}$
}

\begin{abstract}
RESUMO: Esse artigo tem o objetivo de aumentar a compreensão do processo de escolha de roupas infantis. Para alcançar esse objetivo, recorreu-se a extensa revisão bibliográfica e a um estudo exploratório com seis consumidores, quatro gerentes de produtos e quatro gerentes de lojas. Tais procedimentos permitiram identificar os principais atributos influenciadores para a satisfação com o consumo de roupas infantis, agrupados em três grandes famílias: características do produto, produto como meio de expressão e aspectos extrínsecos ao produto. A seguir, desenvolveu-se um estudo quantitativo para explorar a relação entre essas três dimensões e a avaliação da satisfação com a compra e o uso do produto, pelo desenvolvimento de um modelo de equações estruturais para a predição do nível geral de satisfação do consumidor. O estudo foi realizado com uma amostra de 385 consumidores freqüentadores de dois centros comerciais, um calçadão popular e um shopping center na grande São Paulo. O modelo estrutural mostra-se robusto, com $\mathrm{R}^{2}$ ajustado de $67 \%$ e associa a satisfação às características do produto, à sua aparência e à moda.
\end{abstract}

PALAVRAS-CHAVE: Satisfação, Comportamento do consumidor, Varejo de vestuário, Mercado Infantil.

ABSTRACT: This article aims to improve the understanding of children's clothing purchase and consumption decisions. The documental research and the exploratory study - consisted of in-depth interviews with six consumers, four product managers and four store managers - have enabled the identification of three main satisfaction antecedents: product characteristics, product as way for expression and product extrinsic attributes. Subsequently, a quantitative study was carried out with 385 consumers from two different neighborhoods of mid-class and peripheral shopping areas of São Paulo. For the analysis of the results, structural equation modeling was used for measuring the association among the three antecedent dimensions and consumption overall satisfaction. The regression model is robust and has a good fit, presenting an adjusted $R^{2}$ value of $67 \%$. Overall satisfaction is associated to product characteristics, design and fashion trends.

KEY WORDS: Satisfaction, Consumer Behavior, Fashion Retailing, Children's Market.

\footnotetext{
${ }^{1}$ Artigo Recebido em 09.01.2008. Revisado por pares em 17.11.2008. Recomendado em 02.12.2008 por Denise Del Pra Netto Machado (editora). Publicado em 08.12.2008.

Organização Responsável pelo periódico: Universidade regional de Blumenau - FURB.

${ }^{2}$ Docente do curso de Marketing da USP -EACH - efrederico@usp.br

${ }^{3}$ Docente do curso de Marketing da USP - efrederico@usp.br
} 


\section{INTRODUÇÃO}

A satisfação do consumidor é uma questão fundamental a todas as organizações que desejam criar e manter vantagem competitiva num mercado altamente concorrido. A satisfação do consumidor é fonte de feedback sobre a qualidade das decisões de marketing de uma organização, influenciando decisivamente a formação da intenção de compra futura do consumidor (Goode, 2002). De acordo com Goode (2002), consumidores satisfeitos costumam fazer propaganda boca-a-boca sobre uma experiência de compras positiva, afetando diretamente a viabilidade e a lucratividade de uma firma. O mercado de vestuário está cada vez mais concorrido, com um grande número de empresas disputando as preferências do consumidor, tornando oportuna a questão de ampliar o conhecimento sobre o tema da decisão de compra de vestuário e sua associação com a satisfação do consumidor, de forma a adequar as estratégias de marketing das empresas a esse processo.

Crianças desempenham um papel de crescente importância no mercado de consumo, exercendo influência relevante na alocação de recursos em diversas categorias de produtos, dentre elas vestuário, uma categoria de produtos de alto-envolvimento para a maioria dos consumidores (Hogg, Bruce e Hill, 1998; Darian, 1998; Chen, Au e Li, 2004). Entretanto, se a escolha de roupa para adultos já pode ser uma equação bastante complexa, no caso das crianças ela é ainda mais difícil, seja pela maior dificuldade em as crianças entenderem e expressarem suas motivações, seja pelo fato de a escolha ser compartilhada entre os pais e os filhos.

Dessa forma, esse estudo pretende aumentar a compreensão do processo de escolha de roupas infantis. Esse objetivo geral compreende quatro objetivos específicos, a saber:

1. Investigar se há fidelidade à loja ou marca;

2. Investigar as motivações para a compra de roupas infantis;

3. Investigar como o processo decisório é compartilhado por pais e filhos;

4. Investigar os principais determinantes da satisfação do consumidor durante o processo de seleção e consumo de roupas infantis, na opinião dos pais.

Conforme será detalhado no próximo tópico, a satisfação com o consumo dos produtos é decorrente dos atributos tangíveis e simbólicos das roupas. Ainda, aspectos extrínsecos ao produto (como a ambiência da loja ou a qualidade do atendimento) também influenciam no processo decisório do consumidor. Há então três hipóteses preliminares de pesquisa:

H1: Os aspectos tangíveis do produto influenciam a satisfação com o consumo de vestuário infantil;

H2: Os aspectos simbólicos do produto influenciam a satisfação com o consumo de vestuário infantil;

H3: Os aspectos extrínsecos ao produto influenciam a satisfação com o consumo de vestuário infantil.

O presente artigo está dividido em mais quatro partes. A seção 2 compreende a revisão da literatura e a sua relação com o referencial teórico utilizado, de forma a estabelecer as bases conceituais para o desenvolvimento do modelo a ser testado. A seção 3 aborda o método de pesquisa utilizado e suas diversas fases, enquanto que a seção 4 analisa os resultados do modelo. Finalmente, a seção 5 aborda as implicações gerenciais, as limitações e as conclusões da pesquisa. 


\section{REVISÃO DA LITERATURA}

\subsection{Atributos influenciadores para a decisão de consumo de roupas infantis}

São os aspectos que os consumidores consideram quando comparam as alternativas oferecidas no mercado. Os atributos refletem as preferências do consumidor, seus valores, estilo de vida, motivações, conhecimento e experiências (Forney, Park e Brandom, 2005), sendo fundamentais para a compreensão das suas escolhas. Eles podem ser tangíveis e baseados em características observáveis ou baseados em aspectos abstratos como beleza, valor e caimento (Abraham-Murali e Littrell, 1995). Os autores ainda classificam os atributos em duas categorias: aspectos intrínsecos ao produto (ex: composição têxtil) e os aspectos extrínsecos, que não estão contidos no produto em si (ex: marca, embalagem e preço), mas que interferem no processo decisório do consumidor, conforme apresentado na figura 1. Abraham-Murali e Littrell (1995) aprofundaram a investigação e com base nos resultados obtidos, classificaram os atributos pela aparência, pelo desempenho, como meio de expressão e pelos aspectos extrínsecos.

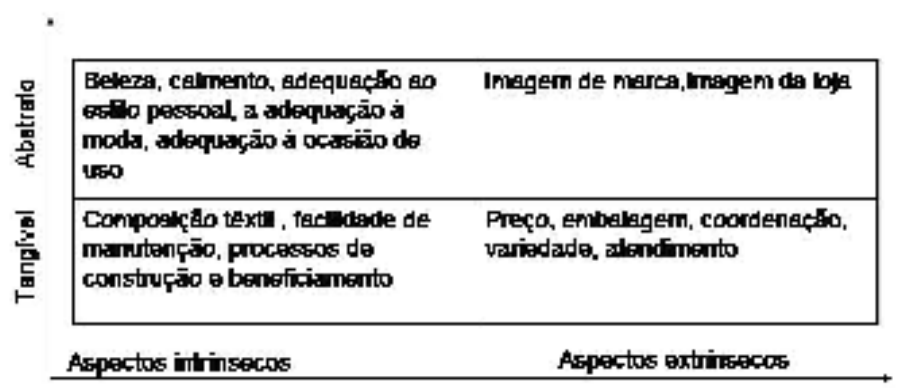

Figura 1: Características do produto

Fonte: Tipologia baseada em revisão bibliográfica efetuada pelo autor

A literatura aponta que os atributos principais para a escolha de roupas englobam a qualidade, o conforto, o caimento, o design do modelo, o estilo pessoal, a possibilidade de coordenação com os outros itens, a adequação à moda, a ocasião de uso, a facilidade de manutenção, o preço e a loja/marca. Durante o processo de revisão bibliográfica, observou-se que vários conceitos, como qualidade, são avaliados pelos consumidores com base em elementos funcionais, emocionais, cognitivos e sensoriais. Qualidade é um conceito multidimensional. Apesar de boa parte dos indicadores que compõem o conceito de qualidade se relacionar com o desempenho, outros como o acabamento e o caimento do produto, por exemplo, são associados à aparência do produto (Tselepis e de Klerk, 2004). Com base no trabalho desses autores e para não comprometer a priori a unidimensionalidade dos blocos conceituais, os atributos influenciadores da decisão de compra investigados durante a revisão da bibliografia e do estudo exploratório foram reordenados e apresentados em três grandes famílias: características do produto, produto como meio de expressão e aspectos extrínsecos.

\subsection{Características do produto}

\subsubsection{Qualidade como influenciador do desempenho e da aparência}

Para Tselepis e de Klerk (2004), qualidade é conceituada como o conjunto de características do produto que tem a capacidade de satisfazer as necessidades explícitas e implícitas dos consumidores, sendo derivada de aspectos intrínsecos e extrínsecos ao produto. Vários aspectos intrínsecos compõem o conceito de qualidade: os materiais empregados, a construção dos tecidos, o conforto proporcionado e a durabilidade, interferindo no desempenho e na funcionalidade do produto, como agasalhar, proteger e possibilitar o movimento com conforto. As roupas de ginástica devem conter fibras têxteis que permitam movimentação, assim como os tênis para corrida devem absorver o impacto do pé com o solo. 
Características associadas à aparência também estão relacionadas com a qualidade do produto. Os processos de beneficiamento nas fibras, como a mercerização, e o acabamento da confecção das peças interferem na percepção de beleza da peça.

\subsubsection{Caimento}

A percepção de qualidade também é influenciada pelo caimento da peça. Diversos estudos tratam da influência do caimento na decisão de compra e satisfação dos consumidores (Wall, Dickey e Talarzyk, 1978; Tselepis e de Klerk, 2004; Chen, 2004; Otieno et al, 2005; Alexander et al, 2005). Caimento contribui para o conforto e o bem-estar social e psicológico do consumidor, e é definido como a forma com que uma peça de roupa se ajusta adequadamente a um corpo. Tselepis e de Klerk (2004) argumentam que uma roupa com bom caimento deve ser confortável para usar, permitir movimentação, sem sobrar demais, deve ser esteticamente aceitável e dentro das tendências da moda. Quando o caimento é um componente da qualidade, os consumidores enfatizarão os aspectos funcionais, pronunciadamente o conforto. $\mathrm{O}$ caimento se relaciona com a aparência quando a roupa não deforma o corpo e segue os requisitos da moda. Ainda, Arbuthnot, Slama e Sisler (1993) apontam que, além da qualidade e do caimento, os elementos determinantes para a decisão de compra estão relacionados ao estilo e o design do produto. Esses dois elementos transcendem a questão da aparência, denotando a utilização da roupa como meio de expressão.

\subsection{Produtos como forma de expressão}

Os consumidores mirins devem ser analisados pelo contexto social, dada a influência dos pais, dos grupos de referência, dos ídolos e da propaganda (Hogg, Bruce e Hill, 1998). De acordo com Hite e Hite (1994), se os pais repetidamente escolhem uma marca, as crianças irão considerá-la boa. Por sua vez, roupas são produtos em que as crianças têm forte identificação e reconhecimento de marca (Hogg, Bruce e Hill, 1998). A imagem de uma roupa não é somente determinada por suas características físicas; roupas de moda comunicam significado simbólico (Miranda et al, 1999). Foram identificadas cinco dimensões da atitude em relação ao consumo de moda: aparecer, ser, parecer, idealizar e inovar; e cada uma delas pressupõe um estilo de relacionamento social. O estilo pessoal é a manifestação de aspectos comportamentais, expressos geralmente sob a forma de padrões de consumo, particularmente de vestuário, baseado no modo de expressar-se de um grupo ou de um período histórico.

Hogg, Bruce e Hill (1998) constataram que meninos facilmente interpretavam o significado simbólico da associação entre marcas de roupas e jogadores famosos de diferentes esportes. Chen (2004) e Ross e Harradine (2004) destacam que há diferenças entre as preferências das crianças de faixas etárias entre 5 e 10 anos. Para ambos, as crianças a partir dos 5 anos expressam preferências próprias baseadas em quatro aspectos influenciadores: pais, propaganda, conformidade a um grupo de referência (normalmente os colegas mais populares da escola) e expressão de individualidade. Para crianças em fase pré-escolar (de 1 a 4 anos de idade), os pais, decisores com maior poder de persuasão, enfatizam a qualidade dos tecidos e o conforto da criança. A partir dessa idade, a criança passa a interferir na decisão de compra e já se começa a observar que o vestir transcende a uma simples necessidade utilitária. Crianças passam a usar roupas para se identificar com um grupo social, projetar uma imagem positiva, melhorar sua aparência e expressar diferenciação (Hogg, Bruce e Hill, 1998; Tselepis e De Klerk, 2004; Ross e Harradine, 2004), exigindo um maior requisito por marcas, moda e modelos, buscando evidenciar um estilo pessoal.

\subsubsection{Moda, estilo e design}

Design é um componente importante nos bens de consumo. North et al (2003) identificaram que o design do modelo e o estilo são os atributos mais importantes de uma 
peça de vestuário, seguido pelo preço, quando a mulher está tomando a decisão de compra. Moda é um fator que interfere no design e no ciclo de vida dos produtos. Pesendorfer (1995) define moda como os designs, produtos e comportamentos sociais mais aceitos durante período limitado. Para Sproles (1981), o conceito de moda é o fenômeno cíclico temporário adotado pelos consumidores por tempo e situação particular. É também o processo de adoção de símbolos que permitem ressaltar a identidade individual (Miller et al, 1993).

North et al (2003) graduam o fenômeno da moda por meio da variável temporal. Para eles, moda é o estilo de vestir predominante de um determinado período que pode durar de um a dois anos (North et al, 2003). Ainda, há o "look" passageiro que é denominado de "modinha", com duração de menos de seis meses. Se uma tendência de moda persiste ao longo do tempo, ela se transforma num clássico. Este visual é aquele que está sempre disponível sem grandes alterações, cujas formas e cores são apropriadas em diversas ocasiões, sendo aceitas por diversos grupos de consumidores. Outros consumidores privilegiam conforto e praticidade, preferindo roupas casuais, confeccionadas com tecidos naturais e texturas suaves. Portanto, além das implicações sociais, a moda tem implicações econômicas para muitos grupos de consumidores. Visto a sua dinâmica, a moda é acompanhada por um processo de contínua inovação, forçando a renovação freqüente dos produtos, pela obsolescência dos designs ditados pelas tendências de moda precedentes.

Os consumidores se identificam com vários estilos, cada qual com uma proposta própria de design. No caso das crianças, o processo de escolha é compartilhado com os pais. Darian (1998) investigou o processo de decisão de pais e filhos na compra de roupas infantis. Os resultados apontaram para uma participação compartilhada de pais e filhos no processo de decisão de compra. Na maioria dos casos, os pais sugerem as lojas e ajudam os filhos a se localizar e a selecionar os produtos. A interação entre pais e filhos é normalmente colaborativa e a decisão consensual; o papel dos pais é facilitar a busca pelo produto com o tamanho certo e fazer sugestões sobre combinações. Darian (1998) conclui que os modelos e as cores dos produtos devem agradar tanto pais e filhos para que a compra seja realizada. Darian (1998) constatou que as compras aconteceram em $81 \%$ das vezes em que não houve desacordo nos modelos e somente em $63 \%$ nas vezes em que pais e filhos não concordaram. Percentuais similares foram constatados quando a discussão envolvia controvérsia sobre as cores dos produtos. Portanto, a possibilidade de ocorrência da compra da roupa está condicionada à avaliação do produto por pais e filhos. Os resultados da pesquisa identificaram que os pais usualmente avaliam todos os atributos (modelo, cor, qualidade, preço, estilo, facilidade de manutenção), enfatizando qualidade e preço como aspectos influenciadores da decisão, enquanto que as crianças enfatizam o modelo, o estilo, a cores e as marcas socialmente aceitas pelo grupo de referência.

\subsection{Fatores Extrínsecos}

Em muitos casos, o varejo procura posicionar suas marcas com o objetivo de serem atrativas não somente do ponto de vista econômico, mas também do ponto de vista social. (Carpenter et al, 2005). Para atingir esse objetivo, esses varejistas buscam oferecer ao consumidor uma experiência de compra que seja prazerosa e diferenciada das outras lojas, no esforço de conquistar e manter a sua fidelidade e a continuidade do relacionamento. Para o consumidor, a compra deve proporcionar valor utilitário e hedônico. $\mathrm{O}$ valor utilitário decorre da eficiência da compra, enquanto que o valor hedônico é resultado de uma experiência agradável (Babin et al, 1994 e Mathwick et al, 2002). Carpenter et al (2005) listam os recursos utilizados pelos varejistas para proporcionar uma experiência de compra compensadora aos consumidores: atmosfera e ambientação do ponto de vendas, atendimento, apresentação dos produtos, organização de eventos dentro da loja e a propaganda. 
Há também fatores extrínsecos de valor utilitário. Chen (2004) argumenta que, além da qualidade e o design do modelo como os principais determinantes intrínsecos da escolha de uma roupa, os consumidores valorizam sobremaneira a possibilidade de coordenação dos produtos já comprados com aqueles em exposição na loja. Finalmente, deve-se considerar o preço cobrado pelo produto. Chen (2004) avalia que os varejistas devem oferecer produtos com estilo, atualidade e qualidade para satisfazer os consumidores, que estão cada vez mais orientados a buscar valor e não simplesmente preço.

\subsection{Satisfação}

Giese e Cote (2000) apresentam uma extensiva revisão do estudo sobre satisfação do consumidor. Basicamente a literatura apresenta a satisfação como um conceito que abrange três aspectos gerais:

1. A satisfação reflete respostas de caráter afetivo, cognitivo e conativo;

2. A satisfação é baseada na avaliação de aspectos funcionais e emocionais (necessidades e desejos) de produtos e daqueles associados à experiência da compra;

3. A satisfação se expressa antes e durante a compra, como uma expectativa, imediatamente após a compra (satisfação com a experiência da compra), e durante e após o consumo, com o uso do produto.

De acordo com Tse e Wilton (1988) a definição de satisfação envolve a percepção do consumidor, que avalia a discrepância entre as suas expectativas antes do consumo e a experiência efetiva. Giese e Cote (2000) propõem que os componentes principais da satisfação do consumidor são mais influenciados por aspectos afetivos, sendo focalizados na escolha, aquisição e consumo do produto. Esta resposta afetiva encontra ressonância nos estudos sobre confiança e fidelidade no relacionamento. Diversos autores (Morgan e Hunt, 1994; Geyskens et al, 1996; Kumar et al., 1994) identificaram duas formas de compromisso: calculado e afetivo, o primeiro baseado em necessidades e o segundo em desejos. Wetzels et al (1998) identificaram que o compromisso afetivo tem um efeito mais forte que o compromisso calculado sobre a intenção de continuidade do relacionamento, uma vez que o relacionamento baseado nos aspectos racionais é mais facilmente descontinuado caso apareça uma alternativa comparável. Da mesma forma, a confiança estabelecida entre compradores e vendedores também e fortemente influenciada por aspectos afetivos (Doney e Cannon , 1997; Sahay, 2003; Morrow, Jr, Hansen e Pearson, 2004).

\section{DESENHO METODOLÓGICO}

\subsection{Desenho da pesquisa}

Procedeu-se a um estudo exploratório qualitativo, visando identificar aspectos que não teriam sido observados no levantamento bibliográfico e elaborar o questionário a ser utilizado na pesquisa quantitativa; a um teste piloto, para refinar e adequar o questionário ao jargão do setor e uma pesquisa quantitativa, utilizando equações estruturais, com o objetivo de analisar os aspectos influenciadores da satisfação no consumo de roupas infantis.

\subsection{Estudo exploratório}

O estudo exploratório procurou trazer indícios adicionais à literatura do fenômeno da satisfação com roupas infantis. Foram entrevistados quatro gerentes de produtos de vestuário infantil e quatro gerentes de lojas que comercializavam, em parte ou na sua totalidade, vestuário infantil. Dado o interesse de um varejista sobre o tema, em uma das lojas foi organizado um grupo de discussão com seis consumidoras. As entrevistas foram pouco estruturadas, basicamente questionando tanto os varejistas como os clientes três aspectos: 1) o 
que é estar satisfeito com uma compra; 2) quando isso ocorre e 3) o que motivava os consumidores durante o momento de escolha dos produtos na loja. De acordo com varejistas e consumidores, a definição de satisfação enfatizava aspectos sensoriais ("se sentir bem usando o produto"), percepção de valor ("valeu a pena"), aspectos funcionais ("a qualidade é boa, não desbotou") e aspectos afetivos ("eu gosto da loja, gosto do atendimento"). Os itens constantes da escala para a satisfação foram elaborados a partir do referencial teórico disponível na literatura, baseadas no estudo de Goode (2002), que apresenta características comuns aos indícios encontrados no estudo exploratório.

Além dos atributos influenciadores da satisfação colhidos na literatura, os entrevistados enfatizaram aspectos relacionados à localização do ponto comercial, do acesso ao crédito e do atendimento. A análise do conteúdo das entrevistas e da pesquisa bibliográfica resultou na seleção de vinte e seis itens que inicialmente comporiam os três grupos de fatores influenciadores da satisfação: características do produto, produto como forma de expressão e aspectos extrínsecos ao produto.

\subsection{Refinamento do questionário}

Para a confecção do questionário final, foi aplicado um questionário preliminar em trinta pais consumidores de roupas infantis, em uma rua comercial da cidade de São Paulo. O questionário continha os vinte e seis itens selecionados através da revisão da literatura e pelo estudo exploratório, mais dez itens constantes da escala de satisfação. A principal decisão decorrente da aplicação do questionário preliminar foi o esforço para reduzir o tempo de preenchimento e o número de questões, sem prejuízo à investigação. Os pais abordados estavam acompanhados dos filhos e, portanto, o preenchimento do questionário deveria ser rápido, para evitar que as crianças ficassem impacientes. $\mathrm{Na}$ aplicação do questionário, procurou-se corrigir as falhas de compreensão dos respondentes, principalmente na terminologia do questionário, adequando o texto sem prejuízo de significado. Também foram incluídas questões para o registro de informações sobre a freqüência, continuidade da relação com um varejista e motivações da compra e influência dos filhos na escolha dos produtos.

Foram utilizadas as escalas baseadas nos estudos de Eckman et al (1990) e Forney et al (1999), em que os entrevistados respondiam a indagação "Quando vou às compras, eu procuro por....." para os atributos pesquisados, preenchendo uma escala de 7 pontos, variando de muito importante (7) para pouco importante (1). A escala foi refinada por meio da verificação de sua confiabilidade, com o uso do coeficiente $\alpha$ de Cronbach, seguindo as recomendações de Churchill (1979). Este procedimento é uma medida do grau de consistência entre os diversos itens que compõem uma escala (Hair et al, 1998, p.117). O coeficiente $\alpha$ de cada família foi computado pela análise de confiabilidade dos itens originalmente pertencentes a cada dimensão. O critério utilizado para a exclusão de um item foi o valor da correlação "item-total" corrigida (Nunnally, 1994, p.305). Seis itens com baixos escores foram excluídos e os valores de $\alpha$ recalculados, redundando em vinte itens com $\alpha$ variando de 0,63 a 0,80 . Em se tratando de um estudo exploratório, valores de $\alpha$ em torno de 0,6 já passam a ser aceitáveis (Peterson, 1994).

A escala para satisfação foi desenvolvida a partir da escala validada por Goode (2002) que procurou medir a satisfação do consumidor com bens de consumo, considerando também aspectos afetivos. Os respondentes deveriam atribuir em uma escala de sete pontos, variando de concordo totalmente (7) a discordo totalmente (1), sua opinião sobre dez afirmações abordando aspectos decorrentes da experiência da última compra de vestuário infantil e do uso da roupa adquirida nesse evento. Três dos dez itens foram descartados por meio da análise de confiabilidade da escala. 


\subsection{Determinação da Amostra e Coleta de Dados}

A definição do tamanho da amostra teve como ponto de partida as orientações preconizadas por Hair et al (1998) para a utilização de equações estruturais, em que são necessárias pelo menos cinco observações por variável do modelo, que resultaria em 150 elementos para o presente estudo. Ainda, para viabilizar o acesso aos respondentes, contou-se com a colaboração de um varejista de moda, que possui cerca de vinte e cinco lojas de vestuário localizadas nos principais centros comerciais da grande São Paulo, resultando em benefício para ambas as partes: as dificuldades em se coletar dados dentro do shopping foram contornadas e o varejista pôde ter acesso aos resultados do estudo. O varejista também especificou os dois centros comerciais de sua preferência para realização da pesquisa: um calçadão na cidade de Osasco e um shopping center, sediado em um bairro de classe média da cidade de São Paulo.

Portanto, o caráter da amostra foi não probabilístico, ou seja, os respondentes foram escolhidos de forma intencional no que diz respeito aos locais e às datas das entrevistas. Malhotra (2006) indica que esse tipo de amostragem é usual em pesquisas feitas por varejistas em centros comerciais. Esse procedimento foi adotado em função de não se ter á disposição a distribuição estatística da população - famílias que vivem na grande São Paulo com ao menos um filho entre 5 e 12 anos - nos diversos locais de compra de produtos de vestuário e de acordo com os dias da semana, o que por si só demandaria uma nova pesquisa. Dessa forma, optou-se pela estratégia de entrevistar o maior número possível de pessoas e analisar os dados quantitativamente, tendo em mente, porém, a não representatividade dos resultados da amostra, mesmo tendo sido composta por 385 consumidores de vestuário infantil, sendo 368 questionários válidos (195 provenientes de freqüentadores do shopping e 173 do calçadão). $\mathrm{O}$ alto índice de aproveitamento deveu-se à utilização de pesquisadores para administrar o questionário junto aos entrevistados.

Para não atrapalhar a operação da loja, a coleta de dados foi efetuada entre segundas e quintas-feiras, sendo que não se deveria ultrapassar uma semana em determinado local. A coleta de dados foi realizada durante o final do mês de fevereiro e inicio do mês de março de 2006. Os consumidores, não necessariamente clientes do varejista, foram abordados no calçadão ou nos corredores do shopping e, caso aceitassem participar, eram conduzidos até a loja para não causar transtorno ou objeções por parte da administração do shopping. Ao final do preenchimento, as crianças ganhavam um brinde.

\subsection{Análise dos dados}

Os vinte atributos para a seleção de vestuário infantil foram submetidos à análise fatorial e verificação da confiabilidade para identificar as dimensões preditoras da satisfação. O processo foi também empregado para verificar se os dez itens desenvolvidos seriam adequados para medir satisfação. Para verificar a adequação do modelo desenvolvido e estimar seus parâmetros, procedeu-se à modelagem de equações estruturais com o uso de LISREL 8.7 (Joreskog e Sorbom, 1998).

\section{DISCUSSÃO DOS RESULTADOS}

\subsection{Características da amostra}

\subsubsection{Aonde compram:}

Os compradores de vestuário infantil que freqüentam esses centros comerciais costumam fazer suas compras em butiques, lojas de departamento e lojas populares (lojas de rua, lojas de variedades, hipermercados, feira, camelô). Da amostra entrevistada, 136 (37\%) realizaram a última compra de vestuário infantil em lojas de departamentos, $88(24 \%)$ em 
lojas especializadas e os $144(39 \%)$ restantes em supermercados, lojas populares, feiras e pequenas lojas de bairro. Não há fidelidade a uma única loja, e os respondentes buscam informações para comprar os produtos. Quando se comparam os resultados entre a amostra colhida no calçadão e aquela colhida no shopping center, a diferença é marcante. O gráfico 1 apresenta a distribuição da última compra por formato de varejo.

Enquanto que 54\% dos freqüentadores do calçadão entrevistados realizaram a última compra em uma loja popular (hipermercados, supermercados, lojas de bairro, redes de lojas com produtos de preço baixo, apresentados em bancas, feiras e camelôs), apenas $26 \%$ dos freqüentadores de shopping da amostra procederam dessa forma, utilizando-se basicamente do canal hipermercado e loja de variedades. No caso das butiques a situação evidentemente se inverte: $31 \%$ dos entrevistados no shopping fizeram a última compra em butique, enquanto que esse formato foi eleito por apenas $16 \%$ do grupo do calçadão. As lojas de departamento também são mais preferidas pelos freqüentadores do shopping (85 entrevistados; $44 \%$ do grupo), em detrimento dos freqüentadores de rua (51 entrevistados; $29 \%$ do grupo).

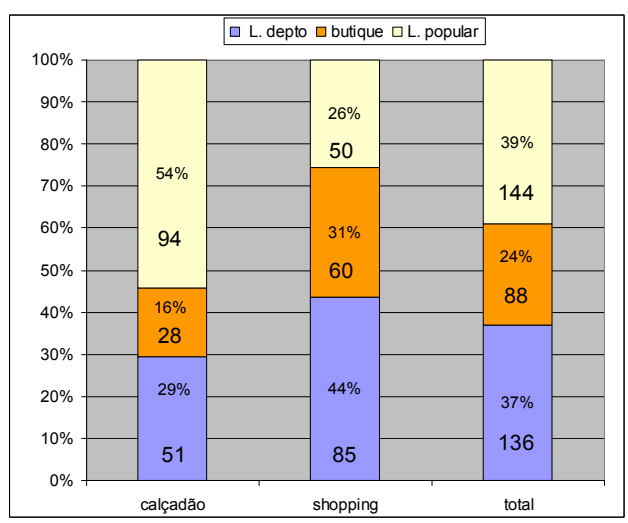

\section{Gráfico 1 - Participação dos formatos de varejo}

Fonte: Resultados da pesquisa realizada pelo autor

\subsubsection{Freqüência e motivação de compra}

Constatou-se uma grande dispersão na freqüência de compras, desde duas vezes no ano até compras mensais. Em função da rapidez de aplicação, o respondente não foi instado a explicar as motivações para tal comportamento. Presume-se que há pais que agem mais racionalmente, trocando o enxoval pelo crescimento dos filhos, liquidações sazonais e mudança de estação climática, e uma parcela que aparentemente busca acompanhar o movimento da moda. Foram identificados quatro motivos predominantemente mencionados para a compra de roupas para as crianças: crescimento dos filhos, mudança de estação climática, ocasiões especiais (aniversário, volta às aulas, dia das crianças, as festas de final de ano e as férias). Finalmente, os pais costumam comprar roupas para presentear parentes e amigos dos filhos.

\subsubsection{Decisão da compra}

Em 155 (42\%) casos a decisão de compra é toda dos pais. A criança decide sozinha em $64(17 \%)$ casos e a decisão conjunta ocorre nos 149 (41\%) restantes. Há dois critérios identificados que permitem às crianças escolherem sozinhas: o tipo de produto, em $61 \%$ (39) das ocorrências e o preço, em 25 (39\%) ocorrências. Aparentemente, os produtos mais caros são decididos em conjunto ou somente pelos pais. O gráfico 2 apresenta os resultados da decisão de compras. 
Surpreendentemente o grupo do shopping apresentou uma maior participação da escolha unicamente pelos pais. Duas suspeitas podem ser levantadas a respeito desse resultado: 1) os produtos do shopping são mais caros e os pais não delegam a decisão aos filhos, 2) há uma tendência do consumidor do grupo de shopping ir à loja desacompanhado, enquanto que os entrevistados da loja de rua costumam ir às compras acompanhados. Uma pesquisa com um número maior de respondentes e que representasse com fidelidade a população poderia responder a essa aparente contradição.

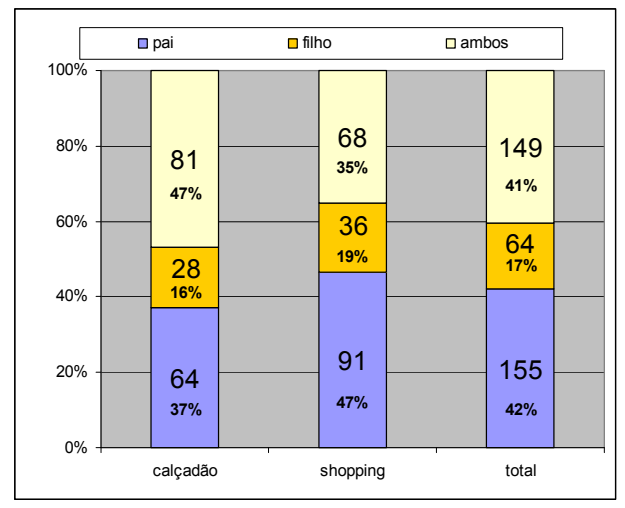

\section{Gráfico 2 - Aspectos da decisão de compras}

Fonte: Resultados da pesquisa realizada pelo autor

\subsection{Dimensões dos atributos}

Primeiramente, procedeu-se a uma análise fatorial exploratória para as escalas propostas, com o uso do software SPSS, a fim de verificar se as variáveis que seriam testadas (utilizadas especificamente neste estudo) eram função de fatores bem definidos. Os resultados estão apresentados na tabela 1. Foi utilizado o método de componentes principais com rotação ortogonal (Varimax). Calculou-se o índice MSA, que varia entre zero e um e quantifica o grau de intercorrelação entre as variáveis e o grau de adequação da análise fatorial (Hair et al, 1998, p.99). O valor obtido foi de 0,89 , denotando adequação da análise fatorial. O scree test indicou uma solução com cinco fatores, com eingenvalues acima de um (Hair et al, 1998, p.104) e variância explicada de $62 \%$.

O critério de importância de uma variável está relacionado à carga fatorial, que, por sua vez, representa a correlação entre a variável e o fator. Foram descartados 7 itens que não tiveram carga fatorial alta ou bem definida, (modelos atrativos, roupas de marca, tecidos de alta qualidade, crédito facilitado, coordenação da coleção, lojas bem localizadas, facilidade de manutenção) para não comprometer a unidimensionalidade dos fatores. Examinou-se a confiabilidade de cada escala, e um dos fatores foi descartado por não atingir os parâmetros preconizados por Churchill (1979). Os outros quatro fatores atingiram valores aceitáveis de $\alpha$ de Cronbach entre 0,70 e 0,82. Os itens componentes de cada fator estão identificados com as respectivas cargas fatoriais apresentadas em negrito.

Tabela 1 - Dimensões dos atributos

\begin{tabular}{|c|c|c|c|c|c|}
\hline Fator & Produto & Beleza & Moda & Loja & (fator não selecionado) \\
\hline Coef. Alfa de Cronbach & 0,82 & 0,74 & 0,72 & 0,70 & 0,45 \\
\hline Variância explicada & $23 \%$ & $12 \%$ & $10 \%$ & $9 \%$ & $8 \%$ \\
\hline Roupas na tendência da moda & & & ,759 & & \\
\hline Roupas com cores atuais & & &, 799 & & \\
\hline Roupas com detalhes diferenciados & ,382 & &, 529 & & ,288 \\
\hline
\end{tabular}

Revista de Negócios, ISSN 1980-4431, Blumenau, v13, n. 1, p. 67 - 92, Janeiro/março 2008. 


\begin{tabular}{|c|c|c|c|c|c|}
\hline Modelos atrativos * & ,271 & ,231 & ,343 & & ,470 \\
\hline Roupas de marca* & & & & & ,774 \\
\hline Variedade &, 551 & & & & ,361 \\
\hline Roupas com durabilidade & ,760 & & & 207 & \\
\hline Roupas com bom acabamento &, 708 & ,274 & & &, 200 \\
\hline Roupas que vestem bem & ,735 & & 205 & & 278 \\
\hline Roupas com tecidos de alta qualidade* &, 542 & & & & ,477 \\
\hline Crédito facilitado* & ,346 & ,388 & & 258 & \\
\hline Coordenação da coleção* &, 556 & ,236 & & & ,444 \\
\hline Roupas que agradem a criança & & ,712 & & & \\
\hline Roupas que agradem o adulto & &, 826 & & & \\
\hline Roupas bonitas & & ,739 & & 221 & \\
\hline Roupas com preço justo & & & &, 660 &, 411 \\
\hline Facilidade em localizar as roupas na loja & & ,335 & & ,683 & \\
\hline Um bom atendimento dos vendedores & ,369 &, 240 & &, 633 & \\
\hline Lojas bem localizadas* & & & ,375 & ,216 & ,324 \\
\hline Facilidade de manutenção* & ,489 &, 256 & & &, 451 \\
\hline \multicolumn{6}{|c|}{$\begin{array}{l}\text { Extraction Method: Principal Component Analysis. Rotation Method: Varimax with Kaiser Normalization. } \\
\text { Cargas fatoriais abaixo de } 0,2 \text { foram suprimidas da tabela } \\
\text { * Itens excluídos } \\
\text { Fonte: Saída do SPSS }\end{array}$} \\
\hline
\end{tabular}

A dimensão Produto está associada às características de qualidade do produto e à amplitude de alternativas à disposição do consumidor. São aspectos tangíveis, que podem ser objetivamente avaliados pelos consumidores, sendo consistentes com o atributo de desempenho identificado por Forney et al, 2005 e Abraham-Murali e Littrell (1995) e com o critério físico/qualidade (Forney et al, 1999). A variância desse fator é maior quando comparada às demais dimensões. Isto indica que a dimensão do produto aparentemente contribui mais fortemente para a decisão de compra dos consumidores. O fator Beleza está relacionado com o julgamento estético de pais e filhos sobre a adequação do produto e é a dimensão conectada ao critério estético (Forney et al, 1999). Moda é o fator associado à dimensão produto como meio de expressão (Abraham-Murali e Littrell, 1995). Os consumidores utilizam a moda como meio de diferenciação e seleção dos tipos desejados para a interação social (Miranda et al, 1999). O fator Loja abrange os aspectos extrínsecos como preço, atendimento e visual merchandising dos produtos.

A tabela 2 apresenta o resultado da análise de correlação para os quatro fatores resultantes. Para a operacionalização de cada fator foram utilizadas as escalas somadas dos itens componentes. A validade dessas escalas está alicerçada com base nos resultados obtidos pela análise fatorial exploratória, na fraca correlação entre os fatores e nos bons índices de confiabilidade. Apesar de não nulas, as correlações entre os fatores não são altas, inferiores a 0,50, o que indica se tratar de fatores distintos.

\section{Tabela 2 - Correlação entre os fatores}

\begin{tabular}{r|rrrr} 
& Produto & Beleza & Moda & Loja \\
\hline Produto & 1,000 & & & \\
Beleza &, 364 & 1,000 & & \\
\hline Moda &, 394 &, 267 & 1,000 & \\
Loja &, 385 &, 481 &, 208 & 1,000 \\
\hline ** Correlation is significant at the 0.01 level (2-tailed). \\
Fonte: Saída do SPSS
\end{tabular}

A tabela 3 apresenta a análise fatorial para as escala da satisfação. A escala se mostrou unidimensional $(\mathrm{MSA}=0,90 ; \alpha=0, .90)$ e a variância extraída superou os $66 \%$. 


\section{Tabela 3 - Satisfação}

\begin{tabular}{l|lc} 
Itens & Abreviatura & Carga Fatorial \\
\hline Meu filho precisava dessa roupa & PRECISO &, 775 \\
Meu filho gostou de ganhar essa roupa & AGRAD &, 835 \\
\hline Eu queria comprar essa roupa & QUERO &, 714 \\
Fiquei satisfeito com essa compra & SATISF &, 805 \\
\hline Gostei de ter feito essa compra & GOSTO &, 848 \\
Valeu a pena ter comprado essa roupa & VALEU &, 885 \\
\hline Me arrependi de ter feito essa compra (reverso) & ARREP &, 822 \\
Fonte: Saída do SPSS & & \\
Extraction Method: Principal Component Analysis. & & \\
Itens excluídos: "Fiquei feliz por comprar essa roupa", "Essa roupa não serviu como eu esperava", "Na próxima \\
vez, vou pesquisar mais antes de comprar"
\end{tabular}

\subsection{Resultados com o uso de modelagem de equações estruturais}

A modelagem de equações estruturais foi realizada com o software Lisrel 8.7, tomando como base os resultados preliminares os fatores obtidos com a aplicação da análise fatorial exploratória. Para melhorar a aderência do modelo, indicadores com carga fatorial alta em mais de um fator foram desconsiderados. Esses indicadores poderiam comprometer a premissa de unidimensionalidade dos construtos. Para tanto, levou-se em consideração o poder explanatório do modelo (pela análise dos índices de aderência absolutos, comparativos e os de parcimônia), sua significância estatística e sua coerência com o referencial teórico.

O modelo resultante apresentou boa aderência $(\chi 2=120$ com 107 graus de liberdade, valor $\mathrm{p}=0,17$, RMSEA $=0,02$ ). Não há indícios de variáveis (offending variables) com valores padronizados próximos a 1,0, que demandariam novos ajustes no modelo (Hair et al, 1998, p. 610). Os demais índices de ajuste se demonstraram adequados (NNFI $=0,99$, $\mathrm{NFI}=0,97, \mathrm{CFI}=1,00, \mathrm{EFI}=0,99$ e $\mathrm{RFI}=0,96)$.

\subsubsection{Modelo de mensuração}

Em geral os indicadores não apresentaram carga fatorial menor do que 0,50 ou próxima de 1,00 (tabela 4), o que indica a boa adequação (Hair et al, 1998). A confiabilidade dos construtos calculada a partir das recomendações de Hair et al (1998, p. 637), entre 0,70 e 0,87, também se apresentou em níveis aceitáveis. Constata-se a maior influência da variável observada "roupas com detalhes diferenciados" como principal componente do fator MODA; da variável "Facilidade em localizar as roupas na loja" para o fator LOJA; da variável "roupas bonitas" para o fator BELEZA; da variável "Roupas com bom acabamento" para o fator PRODUTO e da variável "valeu a pena" para o fator SATISFAÇÃO.

Tabela 4 - Resultados da análise fatorial confirmatória ( $\lambda$-X e $\lambda$-Y)

\begin{tabular}{|c|c|c|c|c|c|}
\hline Item & Moda & Loja & Beleza & Produto & Satisfação \\
\hline Roupas tendência da moda & $0,56(7,82)$ & & & & \\
\hline Roupas com cores atuais & $0,49(6,94)$ & & & & \\
\hline Detalhes diferenciados & $0,67(9,13)$ & & & & \\
\hline Roupas com preço justo & & $0,53(8,67)$ & & & \\
\hline Localizar as roupas na loja & & $0,80(13,84)$ & & & \\
\hline Bom atendimento vendedor & & $0,78(13,46)$ & & & \\
\hline Roupas agradem a criança & & & $0,63(9,46)$ & & \\
\hline Roupas agradem o adulto & & & $0,71(12,07)$ & & \\
\hline Roupas bonitas & & & $0,84(13,80)$ & & \\
\hline Variedade & & & & $0,57(9,12)$ & \\
\hline Roupas com durabilidade & & & & $0,71(11,75)$ & \\
\hline Roupas bom acabamento & & & & $0,62(10,17)$ & \\
\hline
\end{tabular}

Revista de Negócios, ISSN 1980-4431, Blumenau, v13, n. 1, p. 67 - 92, Janeiro/março 2008. 


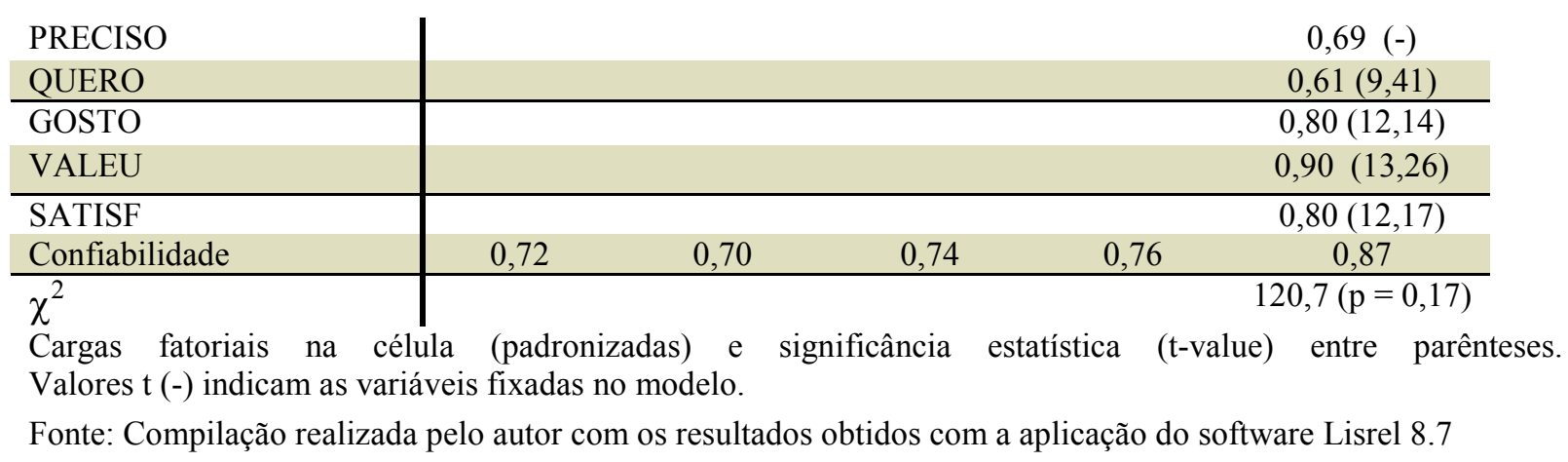

A tabela 5 apresenta a matriz de correlação entre os fatores Moda Loja Beleza Produto Satisfação. Em nenhum par desses construtos verificam-se correlações superiores a 0,90 (Hair et al, 1998), não havendo necessidade de reformulação do modelo.

Tabela 5 - Correlação entre os fatores

\begin{tabular}{lccccc|}
\hline & satisfação & moda & loja & beleza produto \\
\hline Satisfação & 1.00 & & & & \\
\hline moda & 0.40 & 1.00 & & & \\
loja & 0.48 & 0.57 & 1.00 & & \\
\hline beleza & 0.66 & 0.35 & 0.43 & 1.00 & \\
produto & 0.72 & 0.38 & 0.52 & 0.65 & 1.00 \\
\hline
\end{tabular}

Fonte: Saída Lisrel 8.7

\subsubsection{Atributos preditores da satisfação}

Analisando os resultados padronizados obtidos com a aplicação de modelagem de equações estruturais (tabela 6), pode-se observar o efeito predominante da variável produto $\left(\beta_{\text {std }}=0,61\right)$, seguido de beleza $\left(\beta_{\text {std }}=0,22\right)$ e dos aspectos relacionados à moda $\left(\beta_{\text {std }}=0,17\right)$. Aparentemente, verifica-se o maior impacto das características físicas do produto como determinante da satisfação. Os aspectos relacionados à loja não se apresentaram estatisticamente significantes e seus efeitos, mesmo que pequenos, não podem ser considerados.

Tabela 6 - Equação estrutural com parâmetros padronizados

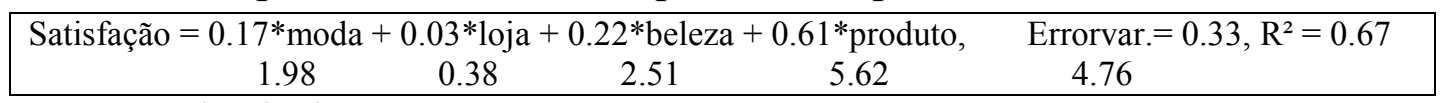

Fonte: Saída Lisrel 8.7

A análise dos resíduos revelou uma distribuição simétrica e em torno do valor médio, sendo que somente três deles resultaram em valores fora do intervalo $\{-2,58 ;+2,58\}$, dentro dos limites recomendados por Hair et al. (1998). A figura 2 apresenta o modelo estrutural resultante. 


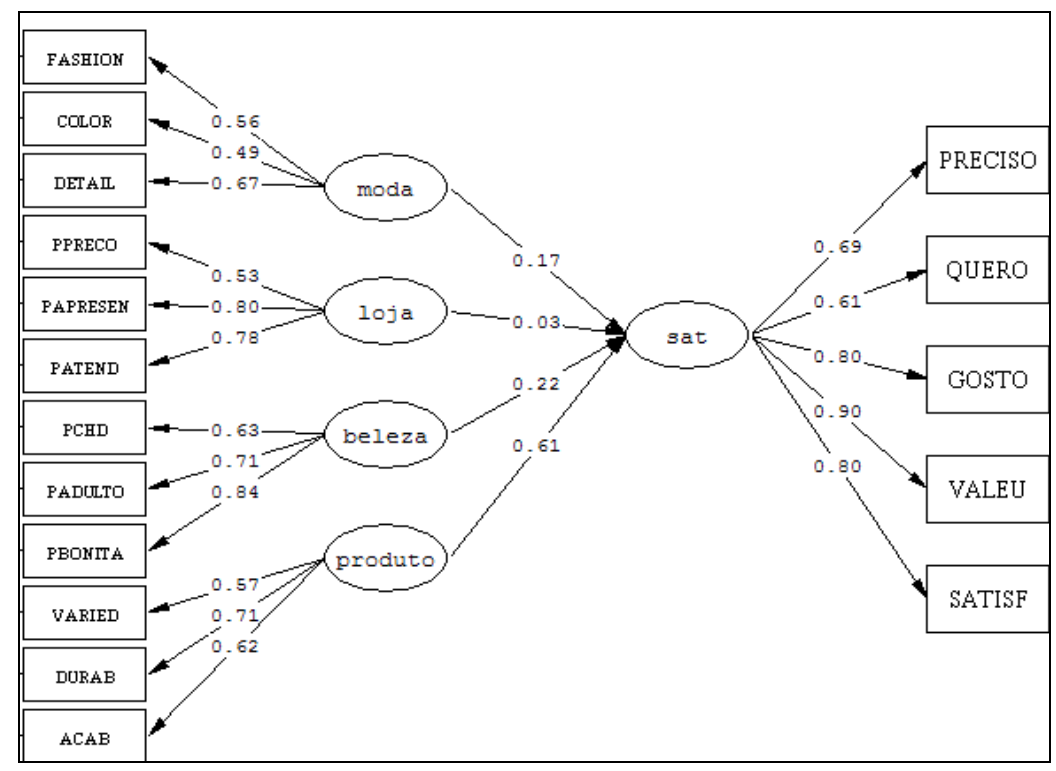

Figura 2- Modelo estrutural resultante

Fonte: Saída do Lisrel 8.7

\section{CONCLUSÕES}

Esse estudo procurou aprofundar o conhecimento sobre a seleção de roupas infantis. $\mathrm{O}$ primeiro objetivo alcançado foi identificar que não há nesses consumidores uma única loja onde são feitas as compras, e que compradores de butiques de shopping também utilizam lojas populares, como hipermercados e vice-versa. Também foram identificados quatro motivos predominantemente mencionados para a compra de roupas para as crianças: crescimento dos filhos, mudança de estação climática, ocasiões especiais com o filho e presentes para parentes e amigos. Essas motivações fazem com que a freqüência de compras varie de forma significativa.

O terceiro objetivo foi identificar o padrão de decisão de compras. Constatou-se que a decisão soberana da criança é minoritária. Normalmente a decisão é dos pais ou compartilhada com o filho (fato mais identificado nas compras feitas no calçadão). Finalmente, procurou-se identificar as dimensões que influenciam a satisfação do consumidor, que consistem de quatro fatores: produto, beleza, moda e loja. As dimensões foram identificadas por meio do teste de um modelo relativamente simples para predição da satisfação do consumidor com vestuário infantil. O modelo sugere ter um bom poder de predição relativamente acurado $\left(\mathrm{R}^{2}\right.$ ajustado de $\left.67 \%\right)$.

Os resultados deste estudo indicam que o nível geral de satisfação do consumidor é decorrente da expectativa dos benefícios funcionais e emocionais da roupa, bem como da efetiva experiência com a compra e com o uso do produto, em concordância com as duas primeiras hipóteses preliminares de pesquisa. A dimensão atributos tangíveis do produto apresenta maior impacto na satisfação do consumidor. Um impacto menor, mas representativo, é decorrente dos atributos simbólicos, relativos à beleza e à adequação às tendências de moda. Ambas as dimensões influenciam a percepção de satisfação, formada por aspectos cognitivos e afetivos e, portanto, H1 e H2 são aceitas. Portanto, crianças usam roupas como forma de expressão e interação social. Tais resultados são compatíveis com aqueles já reportados por pesquisa empírica anterior (Hite e Hite, 1994; Darian, 1998 e Ross e Harradine, 2004), que investigava a satisfação/insatisfação com o desempenho do produto em termos funcionais, sensoriais e emocionais. 
Apesar de não significante, a influência dos aspectos extrínsecos ao produto (representados pela variável Loja no modelo proposto) não deveria ser descartada. Dado que as entrevistas foram efetuadas posteriormente a compra e fora das lojas originárias, pode-se inferir que o impacto dos aspectos extrínsecos ao produto possa ter sido minimizado pelos respondentes. Apesar de não relevante estatisticamente, o momento da venda deve ser tratado com atenção pelos gestores do varejo.

Os resultados apresentados nesse estudo podem ajudar fabricantes e varejistas a compreender os critérios para a seleção de roupas infantis e assim oferecer e promover um melhor sortimento de produtos. Na maior parte dos casos a controvérsia entre pais e filho se dá pelas diferenças de avaliação da adequação do modelo e cores. Portanto, os varejistas devem considerar as necessidades de pais e filhos e oferecer produtos, promoções e serviços que sejam sedutores para ambos. Ainda, independente do consumo se dar em lojas populares ou de marca, não se pode subestimar o papel dos vínculos afetivos e seu impacto sobre a satisfação.

Muitos estudos sobre o comportamento do consumidor apresentam uma série de limitações, da qual esse artigo não foge à regra. $\mathrm{O}$ modelo proposto contém um número limitado de variáveis explanatórias. Estudos futuros devem enfatizar a criação de escalas que reflitam melhor o momento da compra e suas conseqüências. Também a amostra não representa fielmente a população, ainda que seu tamanho tenha superado os requisitos mínimos para o teste do modelo. Outro aspecto não compreendido são as motivações que levam a grande dispersão na freqüência de compras. Por fim, a impossibilidade de entrevistar os respondentes no momento da compra pode ter influenciado a opinião dos pais e minimizado o impacto dos aspectos extrínsecos ao produto.

As seguintes sugestões devem ser destacadas para que haja uma maior compreensão do fenômeno da satisfação do consumidor, de seus determinantes e suas conseqüências: (1) proceder a uma investigação contando com uma amostra ampla, a fim de comparar e generalizar os resultados obtidos para a realidade brasileira; (2) investigar os determinantes e as conseqüências da satisfação e sua relação com a confiança, o compromisso e a continuidade do relacionamento; (3) investigar o fenômeno da satisfação com a experiência da compra; (4) investigar o fenômeno da satisfação para outros ramos do varejo, como eletroeletrônico, alimentos e móveis, identificando as semelhanças e distinções com o consumo de vestuário e (5) investigar os determinantes da freqüência de compras.

\section{REFERENNCIAS}

ABRAHAM-MURALI, L.; LITTRELL, M.A. Consumers' conceptualization of apparel attributes, Clothing and Textiles Research Journal,2005, v. 13, n. 2, p. 65-74.

ALEXANDER,M.; CONNELL, L.J.; PRESLEY.A. B. Clothing fit preferences of young female adult consumers International Journal of Clothing Science and Technology. Bradford: 2005. v. 17, n. 1/2; p. 52-62.

ARBUTHNOT, J.J.; SLAMA, M.; SISLER, G., Selection criteria and information sources in the purchase decisions of apparel buyers of small retailing firms, Journal of Small Business Management, Apr 1993, v. 31, n. 2, p. 12-19.

BABIN, B.; DARDEN, W. ; GRIFFIN, M. Work and/or fun: measuring hedonic and utilitarian shopping value Journal of Consumer Research, 1994, v. 20, p. 644-56. 
CARPENTER J M, MOORE M. , FAIRHURST, A. E.. Consumer shopping value for retail brands. Journal of Fashion Marketing and Management. Bradford: 2005, v.9, n. 1; p. 43-53.

CHEN, X. ; AU, W. M.; LI, $K$. Consumption of children's wear in a big city in Central China: Zhengzhou. Journal of Fashion Marketing and Management. Bradford: 2004. v. 8, n. 2, p. 154-164.

CHURCHILL Jr, Gilbert A. A paradigm for developing better measures of marketing constructs, Journal of Marketing Research, v. XVI, p. 64-73, Feb.1979.

DARIAN, J. C. Parent-child decision making in children's clothing stores International Journal of Retail \& Distribution Management. Bradford: 1998. v. 26, n. 11.,p.421-29.

DONEY, P.M.; CANNON, J.P., An Examination of the Nature of Trust in Buyer-Seller Relationships, Journal of Marketing, v. 61, p. 35-51, Apr 1997.

ECKMAN, M.; DAMHORST, M.L.; KADOLPH, S.J. Toward a model of the in-store purchase decision process: consumer use of criteria for evaluating women's apparel, Clothing and Textiles Research Journal, 1990, v. 8, n. 2, p. 13-22.

FORNEY, J.C., PELTON, W.; CATON, S.T.; RABOLT, N.J., Country of origin and evaluative criteria: influences on women's apparel purchase decisions, Journal of Family and Consumer Sciences, 1999, v. 91 n. 4, p. 57-62.

; PARK, E. J.; BRANDON, L.. Effects of evaluative criteria on fashion brand extensionm, .Journal of Fashion Marketing and Management. Bradford: 2005, v. 9, n. 2; p. 156-165.

GEYSKENS, I; STEENKAMP, J.B.; SCHEER, L.K.; KUMAR, N., The Effects of Trust and Interdependence on Relationship Commitment: A Transatlantic Study, International Journal of Research in Marketing, v. 51, p. 303-318, Oct 1996.

GIESE, Joan L.; COTE, Joseph A.. Defining Consumer Satisfaction. Academy of Marketing Science Review. Vancouver: 2000, v. 2000; p. 1-24.

GOODE, M. M.H. Predicting consumer satisfaction from CD players. Journal of Consumer Behavior, Jun 2002, v. 1, n.4, p. 323 -335.

HAIR JR., J.; ANDERSON, R. E.; TATHAM, R. L.. Multivariate Data Analysis. 5. ed. New Jersey: Prentice Hall, 1998.

HITE, C.F. AND HITE, R.E. Reliance on brand by young children, Journal of the Market Research Society, 1994, v. 37 N. 2, p. 185-93.

HOGG, M.K.; BRUCE, M.; HILL, A.J. Fashion brand preferences among young consumers International Journal of Retail \& Distribution Management. Bradford: 1998. v.26, n. 8., p. 293-301.

JORESKOG, Karl G.; SORBOM, Dag. LISREL 8: Structural Equation Modeling with the SIMPLIS Command Language, Scientific Software International, 1998.

KUMAR, N.; HIBBARD, J.D.; STERN, L.W. The Nature and Consequences of Marketing Channel Intermediary Commitment, Marketing Science Institute, n.. 94-115, Cambridge, MA, 1994.

MALHOTRA, N.K. Pesquisa de Marketing: Uma Orientação Aplicada, Bookman, 2006. 
MATHWICK, C., MALHOTRA, N.; RIGDON, E. The effect of dynamic retail experiences on experiential perceptions of value: an internet and catalog comparison, Journal of Retailing, 2002, v. 78, p. 51-60.

MILLER, C. M.; MCINTYRE, S. H.; MANTRALA, M. K. Toward formalizing fashion theory. Journal of Marketing Research, v. XXX, May, 1993.

MIRANDA, A. P. C.; MARCHETTI, R. Z.; PRADO, P. Moda e autoconceito: produtos como símbolos do eu. Anais do ENANPAD (Encontro Nacional dos Programas de Pós-Graduação em Administração). Foz do Iguaçú/PR, CD-ROM, set. 1999.

MORGAN, R.M.; HUNT, S.D., The commitment-trust theory of relationship marketing, Journal of Marketing, v. 58, p.20-38, Jul 1994.

MORROW Jr, J. L.; HANSEN, Mark H; PEARSON, Allison W. The cognitive and affective antecedents of general trust within cooperative organizations, Journal of Managerial Issues, v. 16, n. 1; p. 48-64, Spring 2004.

NORTH, E.J.; DE VOS, R.B.; KOTZÉ, T. The importance of apparel product attributes for female buyers. Journal of Family Ecology and Consumer Sciences, v.31, p. 41-51, 2003.

NUNNALLY Jum C.; BERNSTEIN Ira H. Psychometric Theory. 3. ed. New York: McGrawHill, 1994.

OTIENO, R., HARROW, C.; LEA-GREENWOOD, G..The unhappy shopper, a retail experience: exploring fashion, fit and affordability. International Journal of Retail \& Distribution Management. Bradford: 2005, v. 33, n. 4; p. 298- 309

PESENDORFER, W, Design innovation and fashion cycles. The American Economic Review. Nashville: Sep 1995. v. 85, n. 4; p. 771-792.

PETERSON, Robert A. A meta-analysis of Cronbach's coefficient alpha. Journal of Consumer Research, v. 21, p 381-391, Sep. 1994.

ROSS, J.; HARRADINE, R. I'm not wearing that! Branding and young children. .Journal of Fashion Marketing and Management. Bradford: 2004, v. 8, n. 1; p. 11-26.

SAHAY, B. S., Understanding trust in supply chain relationships. Industrial Management \& Data Systems, v. 103, n. 8, p. 553-63, 2003.

SPROLES, G. B. Analyzing fashion life cycles - principles and perspectives. Journal of Marketing, v. 45, Fall, 1981.

TSE, D.K..; WILTON, P.C. Models of Consumer Satisfaction Formation: An Extension, JMR, Journal of Marketing Research. Chicago: May 1988, v. 25, n. 2; p. 204.

TSELEPIS, T.; DE KLERK, H.M. Early girls'expectations about the fit of clothes: a conceptual framework. Journal of Family Ecology and Consumer Sciences, v. 32, p. 83- 93, 2004.

WALL ,M.; DICKEY, L.E.; TALARZYK, W. Correlates of Satisfaction and Dissatisfaction with clothing performance. Journal of Consumer Affairs, v. 12, n. 1, Summer 1978.

WETZELS Martin; RUYTER Ko de; BIRGELEN Marcel V. Marketing service relationships: the role of commitment. The Journal of Business \& Industrial Marketing, v. 13, n. 4/5, p. 406423, 1998. 